5. Топоров В.Н. Пространство и текст // Текст: семантика и структура, М., 1983.

6. Топоров В.Н. Миф, Ритуал. Символ. Образ: Исследования в области мифопоэтического: Избранное. - М.: Издательская группа «Прогресс» — «Культура», 1995.

\title{
Английская аббревиатура как лингвистическая особенность on-line общения
}

\section{Корякин Р.А., студент, ГАПОУ РС (Я) «Алданский политехнический техникум», 2. Алдан E-mail: aldan_politeh@rambler.ru}

Научный руководитель: преподаватель Ринчиндоржиева М.Ф.

Настоящее исследование посвящено изучению аббревиационных процессов, являющихся специфической чертой онлайн общения, сравнительно новой формы речевого общения. В данной работе рассматриваются причины появления и быстрого распространения сокращений, анализируются разновидности английских сокращений и способы сокращений. Рассмотрено понятие «аббревиатура» в лингвистике, приведена классификация сокращений по типам.

\section{Понятие «оn-line общение»}

Почему люди выбирают интерактивный способ общения? Можно выделить следующие причины:

1) недостаточное насыщение общением в реальных контактах;

2) возможность реализации качеств личности, проигрывания ролей, переживания эмоций, по тем или иным причинам недостаточных в реальной жизни;

3) неудовлетворенность реальной социальной идентичностью и желание избавиться от нее. В виртуальной реальности не имеют значения такие способы определения социального статуса как внешний вид, возраст, пол. Интернет позволяет конструировать новый образ, воплощая в нем нереализованные психологические запросы. По степени интерактивности коммуникаций разделяют наиболее интерактивные среды общения - чаты и форумы; наименее интерактивные - e-mail и телеконференции (в телеконференции и при общении посредством e-mail общение происходит в режиме off-line, в отличие от чата, где люди общаются в режиме реального времени on-line). По количеству участников, вовлеченных в коммуникативный процесс, выделяют:

1) диалоговую коммуникацию (электронная почта, ICQ);

2) полилоговую коммуникацию (конференции, чаты);

3) однонаправленную коммуникацию (объявления, реклама, отзывы и т.п.).

Язык виртуальной коммуникации не является новым. Он происходит от языка SMS-сообщений, который в свою очередь происходит от арго, используемого молодежью. Новым является лишь способ коммуникации сам по себе. Манера изложения зависит от возраста пользователя и его адресата, в основном, чем они моложе, тем более их общение насыщено различными сокращениями. 


\section{Влияние on-line аббревиатур на нормативный язык}

Анализируя характеристики языка чатов, полного сокращений и усечений, можно выделить его положительные и отрицательные стороны. К безусловным плюсам можно отнести следующие его свойства: времени;

1) Передача большего количества информации за минимальное количество

2) Возможность передачи информации при недоступности адресата;

3) Возможность научиться лаконично и четко формулировать свои мысли;

4) одновременная передача информации и эмоций (могут передавать интонацию устной речи);

5) Возрождение традиции переписки.

Среди отрицательных характеристик выделяются затруднение в понимании содержания и Пренебрежение правилами грамматики и орфографии.

Язык, используемый в чатах в большей степени популярен среди молодежи, подростки пользуются им отчасти потому, что это дает им чувство принадлежности к некой социальной группе. Употребление этого языка для его пользователей походит на обладание секретным кодом, и некоторые действительно изобретают собственные диалекты, понятные лишь членам определенной группы. Язык, широко используемый в Интернете и в СМС-сообщениях, во многих странах никого не оставляет равнодушным: с одной стороны, он широко распространен среди молодежи, про него и на нем пишутся книги, проводятся серии исследований, с другой стороны, у данного уровня владения языком много противников, объединяющихся для борьбы с ним. Существуют даже соответствующие объединения такие как «Комитет борьбы с языком СМС-сообщений и произвольным написанием слов в Интернете». Данный комитет сформирован молодыми людьми от 17 лет, которые призывают использовать произвольное написание слов лишь при переписке с использованием сотовых телефонов, как это и было первоначально.

\section{Разновидности английских сокращений и способы сокращений}

В данной работе нами были исследованы наиболее популярные социальные сети на английском языке, такие как Facebook, Twitter, Instagram. На основе этих исследований можно утверждать, что все сокращения, используемые в процессе виртуальной коммуникации можно разделить на несколько основных групп.

Во-первых, лексическому сокращению подвергаются выражения, выступающие в речи в роли вводных слов со значением отражения порядка мыслей и их связи; замечания о способах оформления мыслей; источника сообщения; целевой направленности сообщения; и сочетания слов в роли вводных предложений:

"BOT" (back on topic); "BTW" (by the way);

Во-вторых, аббревиации подвергаются словосочетания с главным словом глаголом в форме повелительного наклонения:

"RBTL" (read between the lines); $\quad$ "RML" (readmylips);

К третьей группе относятся устойчивые словосочетания:

"CUL8R" (see you later); "TIE" (take it easy);

"I’ll B L8" (I shall be late)

В следующую группу могут быть включены различные знаменательные слова, сочетания слов и предложения с высокой частотой употребления:

"ASAP" (as soon as possible); "HTH" (Hope this help)

"ISP" (Internet service provider); "L8R" (later); 
"B4" (before);

И, наконец, в пятую группу входят эксплетивы, то есть сочетания слов, выражающие отношение говорящего к предмету говорения, но не влияющие на содержание высказывания:

"SH" (shit happens); $\quad$ "ONNA" (Oh no, not again);

Кроме перечисленных акронимов и полусокращении в речи участников чата встречается и третий тип лексических сокращений - усечения:

"tlph" (telephone);

Кроме приведенных примеров усечений, в языке виртуальной коммуникации практически всегда сокращаются предлоги, вводные слова и общеупотребительные выражения:

"bcs" (because) "bf" (before);

К графическим сокращениям, употребляемым в процессе виртуальной коммуникации, относятся следующие группы: "min";

1. Общепринятые графические сокращения, такие, как "etc. ", "т.д. ", "max",

2. Буквенно-числовые сокращения: “L8”, “4U”, “B4”

3. Использование символов вместо слов, идиоматическое письмо: "some \$", "100\%".

Говорить об аббревиатурном взрыве возможно в области «компьютерного пользования». Особенно большое количество аббревиатур характерно для так называемых «чатов». «Чат» (от англ. tochat - болтать) - синхронный вид электронного общения, как в телефонном разговоре, однако обмен «репликами» происходит не в устной форме, а в письменной.

Аббревиация в компьютерном жаргоне представлена различными типами: усечение конечной части слова (semi (от semicolons), jock( от jockey), quest (от question)); усечение начальной части слова (Net (oт Internet)). Но самым популярным типом аббревиации является, пожалуй, буквенное сокращение каких-либо словосочетаний и даже предложений. Например, буквенное сокращение предложений:

DIAFYO - Did I AskForYourOpinion? FOAD - F* Off And Die

GMAB - Give Me A Break $\quad$ GMTA - Great Minds Think Alike

HAND - Have A Nice Day KMA - Kiss My *A

Как видно изприведенных примеров, среди кодируемых предложений встречаются команды для пользователей (RTM, RTFM, RYS), советы (MLNW, NSD, TBYB), просьбы (GMAB, LMK), выраженияблагодарности (TFTI, TFTT), пожелания (HAND, RIP), ругательства (KMA, LAB, LABATYD, RTFM, FOAD, STFU). Здесь необходимо отметить, что аббревиатуры представляют собой эвфемистические возможности для употребления нецензурных слов и выражений, поскольку присутствует некоторая анонимность. Подобная непринужденность общения даже была причиной разработки особого сетевого этикета (Netz-EtiketteoderNetiquette), цель которого была борьба с «сетевыми хамами». Во избежание неприятных последствий в некоторых случаях встречалась следующая расшифровка аббревиатуры RTFM ReadTheFriendlyManual. Некоторые аббревиатуры представляют собой зашифрованные крылатые выражения: GMTA, MLNW, OV.

Ряд аббревиатур представляет собойкреолизованные тексты, т.е. характерно не только словесное изображение, но и зрительный ряд, в большинстве случаев, цифры:

$$
\text { 2L8 - Too Late } \quad 4 \text { - For }
$$




$$
\begin{array}{ll}
\text { B4N - Bye For Now } & \text { BBL8R - Be Back Later } \\
\text { L33T - Elite } & \text { NE1 - Anyone } \\
\text { W8 - Wait } & \text { W8N - Waiting. }
\end{array}
$$

Чаще всего в аббревиатурах используются цифры 8 и 4, чей фонемный состав ['eit] и [fo:] обыгрывается в различных вариациях m[eit], l[eit]r, b[fo:], w[eit], ['fo:]get и т.д.

Подобный прием шифровки используется и по отношению к буквам английского алфавита, например:

$$
\begin{array}{ll}
\text { CU - See you } & \text { CUL - See you later } \\
\text { IKWYM - I know what you mean } & \text { OIC - Oh, I see } \\
\text { U - You } & \text { Y - Why }
\end{array}
$$

При анализе употребления аббревиатур в социальных сетях мы пришли к выводу, что при образовании сокращений пользователи Интернета проявляют удивительную изобретательность и фантазию. Согласно статистике одного из самых крупных сайтов, посвященных сокращениям в сети (www.AcronymFinder.com), в его базе в настоящее время существует 4195875 зарегистрированных английских сокращений, которые являются международными. У нас возник вопрос, пользуются ли данными сокращениями студенты нашего техникума. Поэтому нами было проведено анкетирование среди 100обучающихся, в котором были следующие вопросы:

1. Сталкивались ли Вы с сокращениями английских слов и фраз в Интернете? Например, IMHO, LOL, L8R, SUP, WBW.

2. Понимаете ли Вы их значение?

3. Пользуетесь ли Вы ими при общении в Интернете?

4. Нужно ли Вам больше информации по данному вопросу?

5. Считаете ли Вы, что использование английских сокращений, экономит время и одновременно является модным среди молодёжи?

В результате анкетирования было выявлено, что 45\% обучащихся встречались с сокращениями английских слов, но лишь 15\% имеют представление, как расшифровываются данные сокращения. Также 10\% пользуется аббревиатурами при общении в Интернете. 30\% хотело бы получить дополнительную информацию по данному вопросу.

Одной из особенностей лексического фонда языка Интернета является образование и повсеместное использование различного вида сокращений, что связанно с письменной природой электронной коммуникации. Из-за постоянно убыстряющегося темпа общения в Интернете появляется необходимость передать максимальное количество информации в единицу времени, реализующуюся посредством принципа экономии языковых усилий, что более явно выражается в использовании большого количества аббревиатур.

Таким образом, анализ коммуникации Интернета позволил установить, что аббревиация как явление системы языка находится в развитии, поэтому представляет огромное пространство для исследовательской деятельности.

\section{Список литературы:}

1. Бергельсон М.Б. Конструирование адресата в условиях виртуальной коммуникации [Текст] / М.Б. Бергельсон // Русский язык: исторические судьбы и современность. Труды и материалы. - М., 2004. 
2. Борисов В.В. Аббревиация и акронимия / В.В. Борисов. - М., 2013. - с.38, 124143.

3. Котова О.Е. Структура и семантика англоязычного компьютерного жаргона. Тольятти, 2001.

4. Максимова Т.В. Новые слова современного английского языка // Лингводидактические проблемы межкультурной коммуникации - сборник научных статей. Волгоград, 2011.

5. Скребнев Ю.М. Основы стилистики английского языка. М., 2000.

6. http://www.ivanoff.ru/rus/OZHWEB. htm

7. http://psynet. by.ru/texts/voysk6. htm

8. http://www.instagram.com

9. http://www.facebook.com

10. http://www.twitter.com

\title{
Автобиографическая повесть в эвенской литературе: традиции и новации
}

\author{
Кривочапкина И.В., соискатель, \\ Северо-Восточный федеральный университет, \\ 2. Якутск \\ E-mail: iya krivoshapkin@mail.ru
}

\section{Научный руководитель: д.филол.н., профессор Хазанкович Ю.Г.}

Автобиографические произведения фокусируют внимание на истории формирования и развития личности под влиянием социально-исторических явлений и процессов. Они неразрывно связаны с темой детства. Детство - это период становления полной социальной и психологической зрелости, становления ребенка полноправным членом общества. Но интерес к нему и попытки его исторического осмысления возникают на определенном этапе индивидуального и социального развития. Автобиография - это всегда ретроспективные размышления о времени и о себе. Характерная для русской автобиографической прозы черта - осознать свой частный опыт с точки зрения важности его для других. Автор осмысливает собственную судьбу в контексте исторических изменений в жизни страны. На идейно-концептуальном уровне для автобиографических произведений важны такие понятия, как «время», «эпоха», «век». Здесь личное биографическое время соотнесено со временем историческим. Носителем авторской концепции времени является авторповествователь. Он находится в ином хронотопе, нежели герой-повествователь, следовательно, ему доступно обобщение событий, ему известен «конец истории», что дает возможность заглянуть в будущее, осмыслить причины и последствия произошедшего с ним. Именно автору-повествователю принадлежит взгляд на свою судьбу как на судьбу народа, часть общей истории.

Интересно увидеть отражение этих взглядов в автобиографических повестях первого эвенского писателя Н. Тарабукина и первой эвенской женщины-писателя М. Амамич, творческий временной разрыв между которыми около сорока лет. При общности жанровых особенностей (специфики героя, композиции, сюжета) их 